Iranian Quarterly Journal of Breast Disease. 2019; 12(1):8-18.
Receive: 2018/10/17 Accepted: 2019/4/16

"Corresponding Author: Mahsa Khodayarian mahsa.khodayarian6@gmail.com

Ethics Approval: ir.ssu.medicine.rec.1395.108

\section{Original Article \\ Development and Psychometric Evaluation of a Protection Motivation Theory-Based Scale Assessing the Adherence of Iranian Women Breast Cancer Prevention Behaviors}

\author{
Khodayarian $\mathbf{M}^{1^{*}}$, Peyghambari $\mathrm{F}^{2}$, Mazloomy Mahmoodabad $\mathrm{S}^{1}$, \\ Morowatisharifabad $\mathrm{MA}^{3}$, Lamyian $\mathrm{M}^{4}$ \\ ${ }^{1}$ Social Determinants of Health Research Center, School of Public Health, Shahid \\ Sadoughi University of Medical Sciences, Yazd, Iran \\ ${ }_{2}$ Department of Anatomical Sciences, Faculty of Medical Sciences, Islamic Azad \\ University, Yazd Branch, Yazd, Iran \\ ${ }^{3}$ Department of Ageing Health, School of Public Health, Shahid Sadoughi University \\ of Medical Sciences, Yazd, Iran \\ ${ }^{4}$ Department of Midwifery and Reproductive Health, Tarbiat Modares University, \\ Tehran, Iran
}

\begin{abstract}
Introduction: Breast cancer is the most common type of cancer that has concerned Iranian women. Early detection is a major determinant of disease prognosis. Thus, participation in prevention behaviors is the only available option for women. The aim of this study was to develop and validate a protection motivation theory (PMT)-based scale for assessing the participation of Iranian women in breast cancer prevention behaviors.

Methods: A sequential exploratory mixed methods design was used. In the qualitative phase, 14 semistructured interviews were done with women. After directed qualitative content analysis, primary items were phrased. Validity of the questionnaire was assessed by a panel of experts, calculation of CVR and CVI, and using confirmatory factor analysis. Reliability of the scale was measured using Cronbach's alpha. Then, a cross-sectional study was performed on 420 women. The data were analyzed using SPSS 19 and AMOS 16 software packages.
\end{abstract}

Results: All of the items gained impact scores $>1.5$ in qualitative and quantitative face validity assessment. In the dimension of content validity, 9 items were deleted. Reliability of the questionnaire was acceptable. The final draft of the questionnaire was prepared in two sections including demographics and PMT constructs comprising 56 items and 8 domains. Factor analysis confirmed the fitness of the model representing the measurement theory.

Conclusion: The present study is a pioneer in assessing the applicability of PMT for assessing the participation of Iranian women in breast cancer prevention behaviors. The developed scale has acceptable psychometric properties among Iranian women, and it can be used as a reliable instrument.

Keywords: Sequential Exploratory Mixed Methods Design, Protection Motivation Theory, Directed Qualitative Content Analysis, Psychometrics, Breast Cancer Prevention Behaviors 


\section{طراحى و روان سنجى ير سشنامه مبتنى بر نظريه انكيزش محافظت براى مشاركت زنان ايرانى در رفتارهاى بيشَيرانه از سرطان

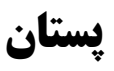

مهيسا خداياريان"'، فاطمه بِيغمبرى"، سيد سعيد مظلومى محمود آباد'، محمدعلى مروتى شريف

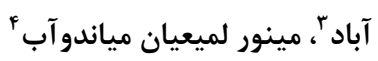

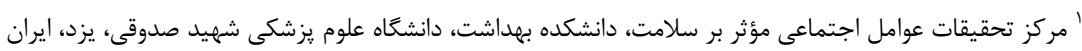

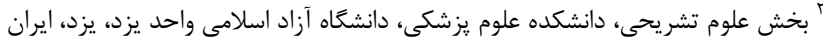

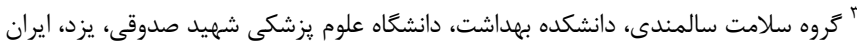

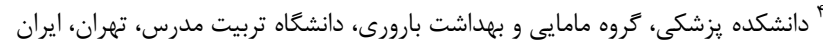

\section{جكيده}

مقدمه: سرطان يستان شايعترين سرطانى است كه زنان ايرانى را نكران نموده است. تشخيص

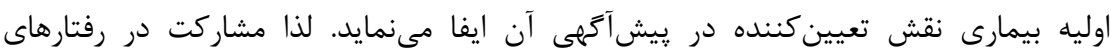

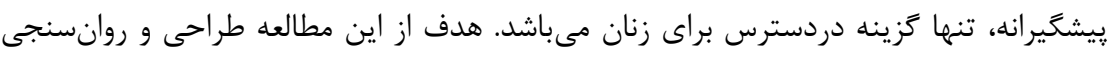

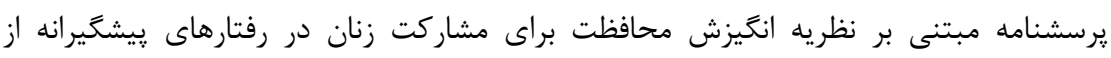
سرطان يستان بود.

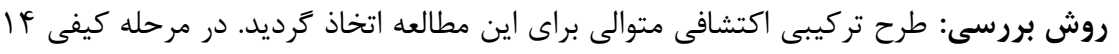

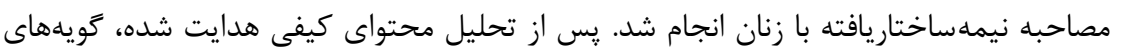

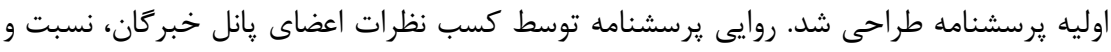

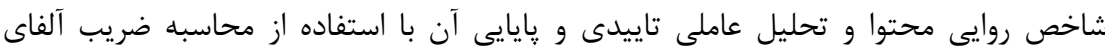

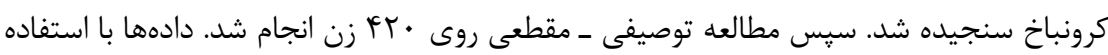

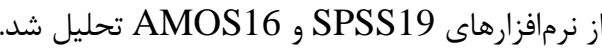

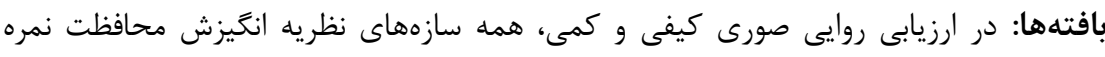

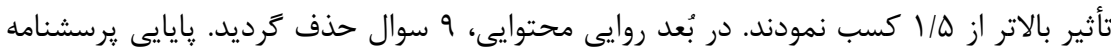

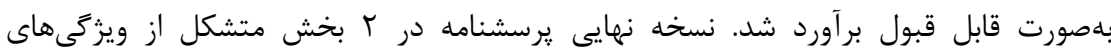

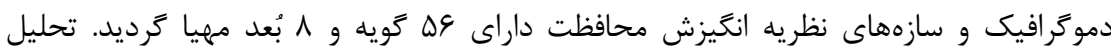

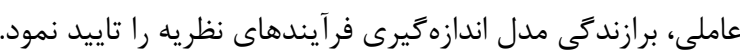

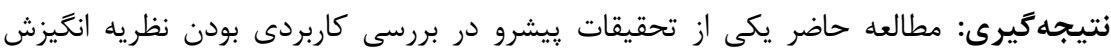

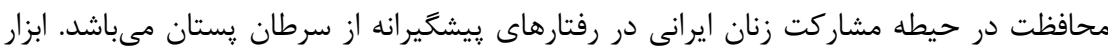

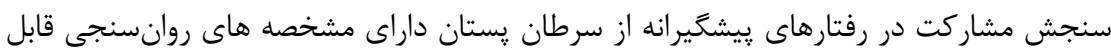

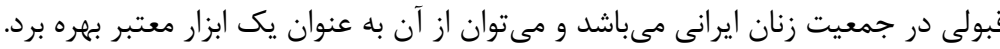

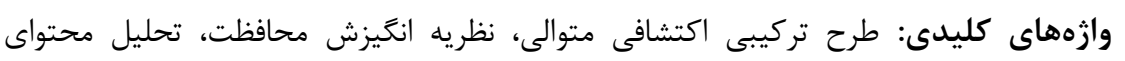

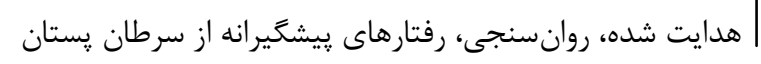

فصلنامه بيمارى هاى يستان ايران

Iran! $\operatorname{lr}(1): 1-11$

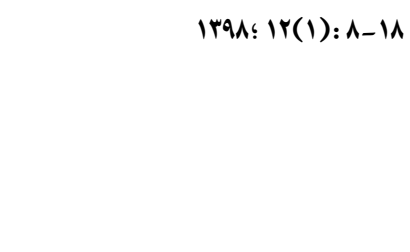

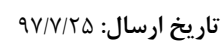

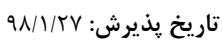

نشانى نويسنده مسئول: مهيا خداياريان mahsa.khodayarian6@gmail.com 
پيشگيرانه از سرطان يستان نشان داد فقدان آكاهى در درك خطر سرطان קستان، عدم توجه به توصيههاى يزشكى، انكار شدت يا وخامت بيمارى، نداشتن نقش فعال

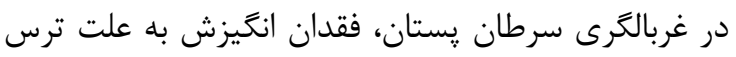

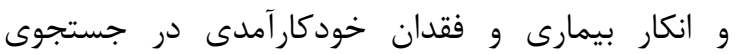
مراقبتهاى يزشكى از عواملى است كه رفتار غربالكرى سرطان يستان را در زنان ايرانى تحتالشعاع قرار داده

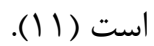
بر اساس مطالبى كه در بالا به آن اشاره شد مشاركت زنان

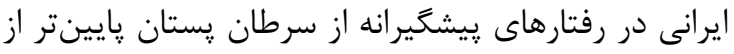

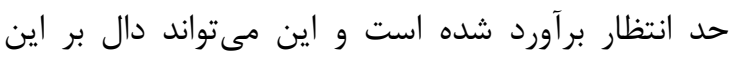
باشد كه زنان ايرانى يا خود را در برابر سرطان يُّان إنان

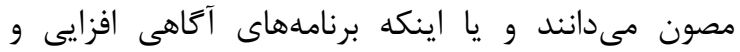

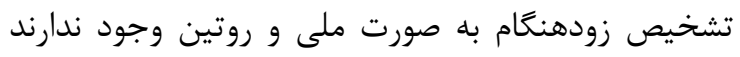
درحالى كه آمار ابتلا به اين بيمارى كشنده رو بنه به افزايش

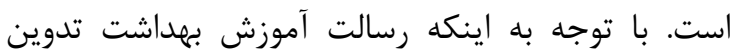

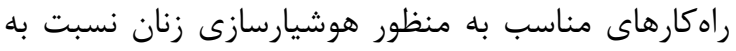

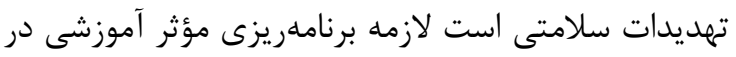

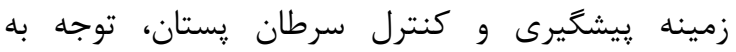

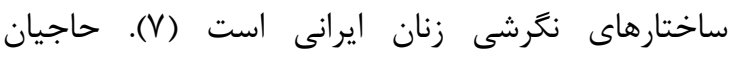

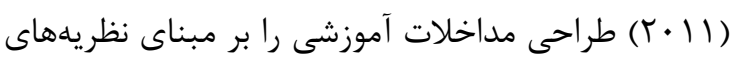
روانشناختى مشهور براى سرطان يستان در كشورهاى در

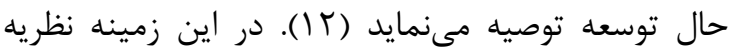

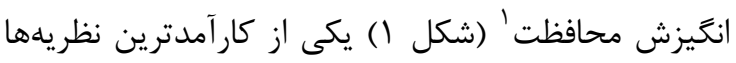

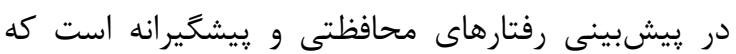
ابتدا بر انخيزش استوار است و سيس به توسعه مهارتهاى

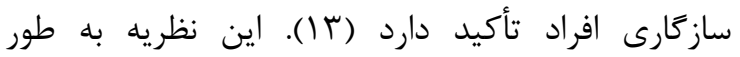

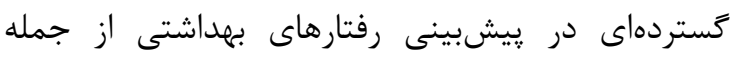

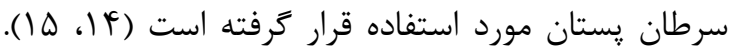

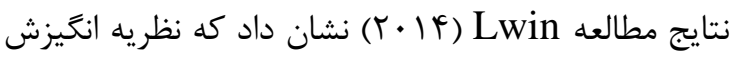
محافظت جارجوب مناسبى در زمينه غربالكرى سرطان

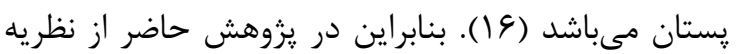

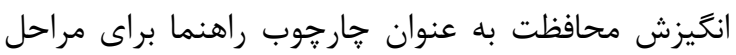
يزولهش استفاده شد.

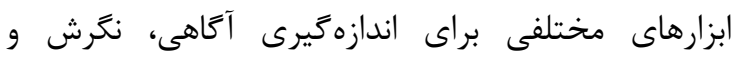
عملكرد زنان ايرانى در ارتباط با مشاركت در رفتئي

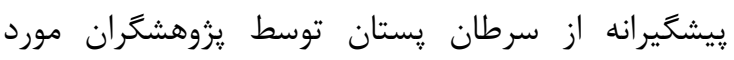

\footnotetext{
${ }^{1}$ Protection motivation theory
}

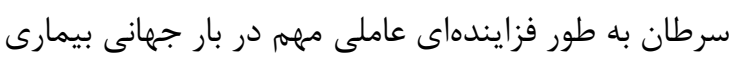

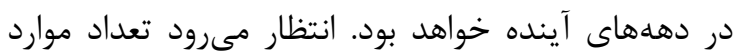

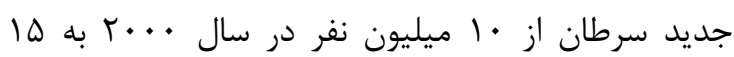

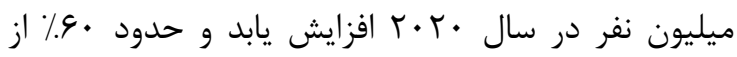
اين موارد جديد در قسمتهاى كمتر توسعه يافته جهان

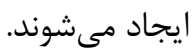
در ايران سرطان يستان رتبه اول بدخيمىها راند راند در ميان

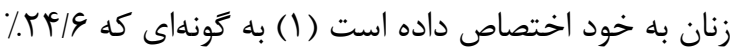

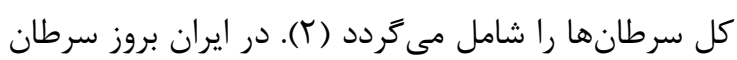

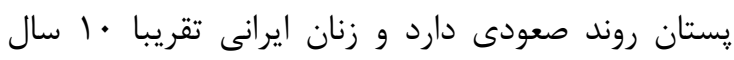
زودتر از همنوعان خود در كشورهاى توسعه يافته به اين

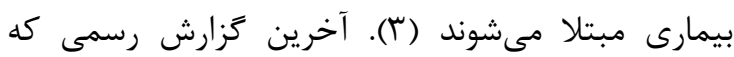

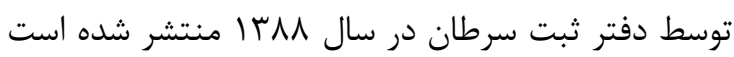
ميزان بروز استاندارد شده سنى سرطان يستان دN/TS

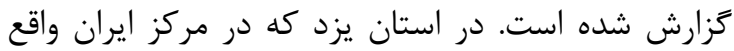

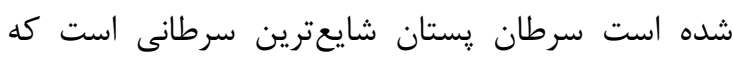
زنان را نكران نموده است و ميزان استاندارد شده سنى آن بـ آن

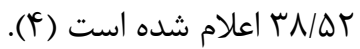
بالا بودن ميزان مركومير ناشى از بيمارى در كشورهاى

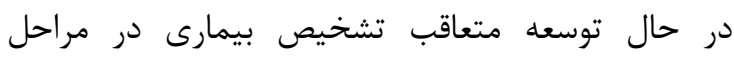
ييشرفته ضرورت برنامهريزى و اجراى برنامههاى غربالكرى

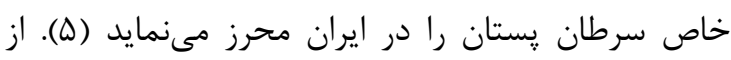

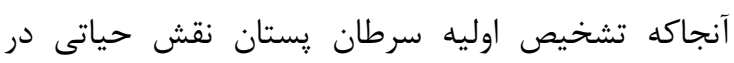

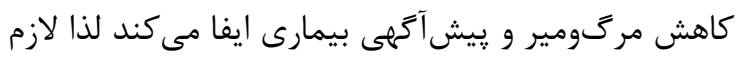
است كه آموزشدهندكان بهداشت و ارتقاى سلامت آكاهى

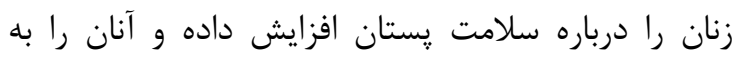

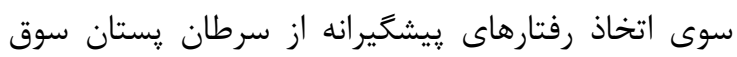

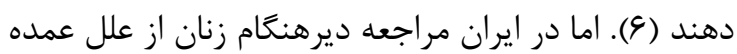

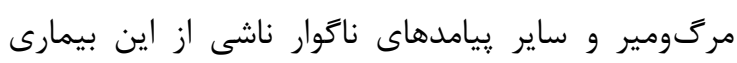

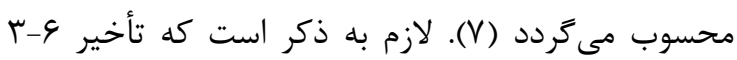

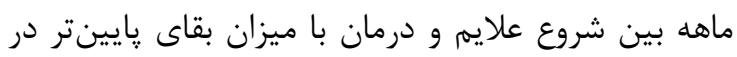

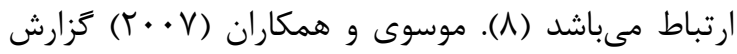

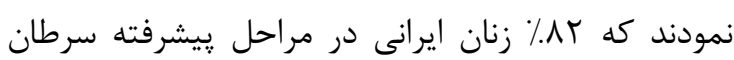

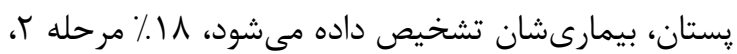
\% مرحله r. VV

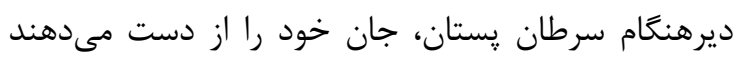

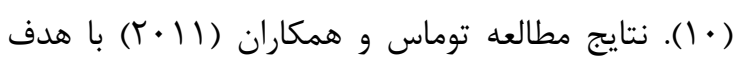
تبيين تجارب و ادراى زنان ايرانى در ارتباط با رفتارهاى 
رفتارهاى بيشگيرانه از سرطان يستان مىباشد. همجنين با

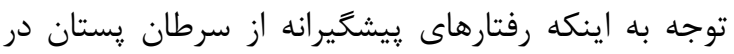
زنان داراى بار فرهنگى بوده و بر اساس مرورى بر مطالعات

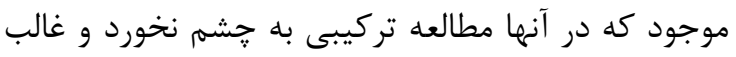
آنها مطالعات كمى محض بوده و ماهيت ساختارهاى نظريه

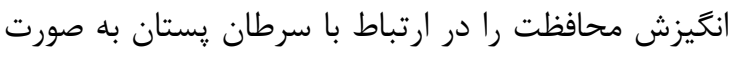

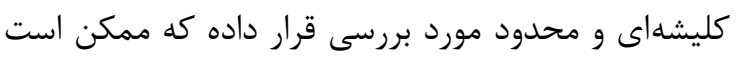
از واقعيتها دور باشد.

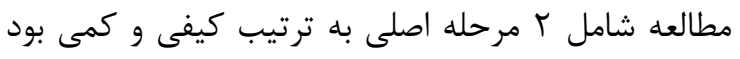

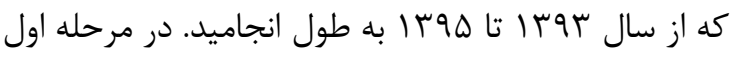

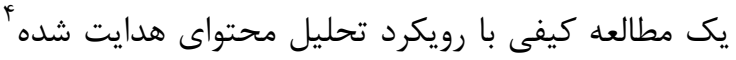
مبتنى بر نظريه انكَيزش محافظت انجام شد. در ابتدا از

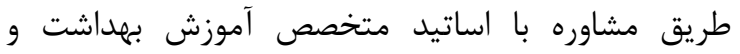

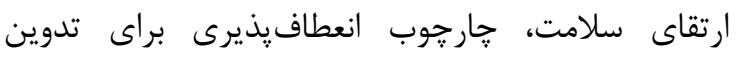

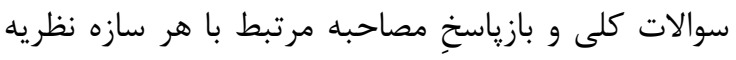
انگَيزش محافظت طراحى و اعتباربخشى گرديد.

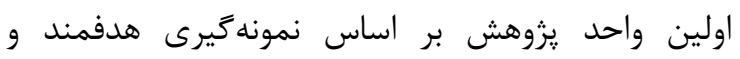

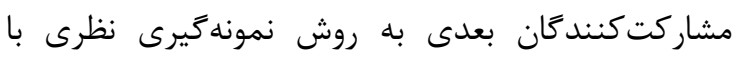

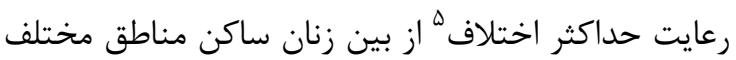

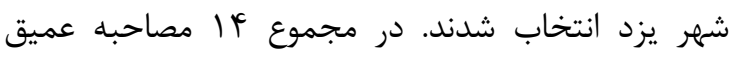

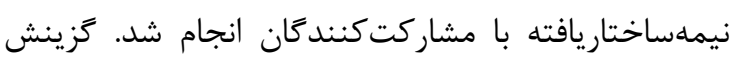
تدريجى مشاركت كنندكان بر اساس مفاهيم در حال ظهور

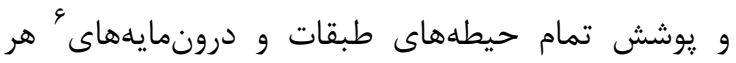

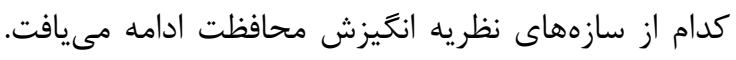

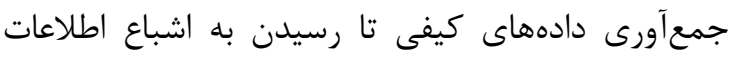

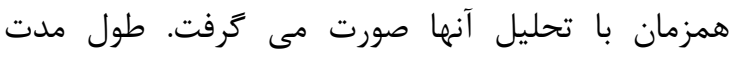

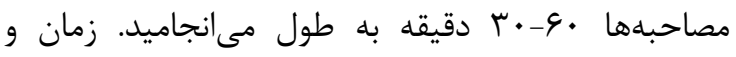

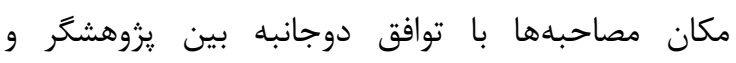

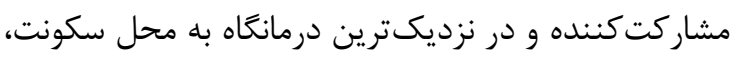

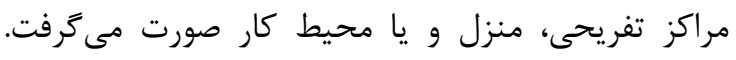

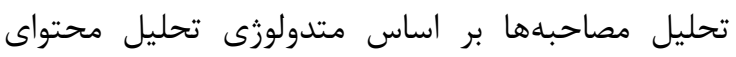

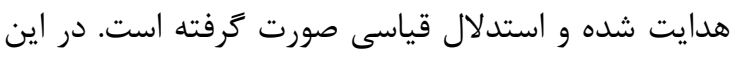

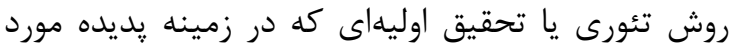

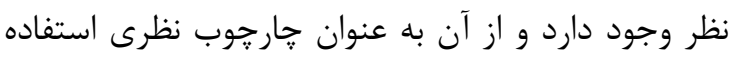

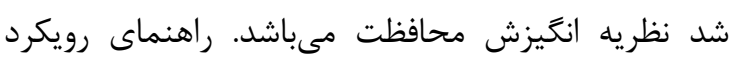

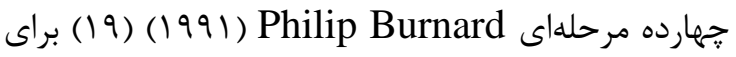

\footnotetext{
${ }^{4}$ Directed content analysis

${ }^{5}$ Maximum variation

${ }^{6}$ Themes
}

استفاده قرار گرفته است كه عمدتاً از ابزار توسعه داده شده

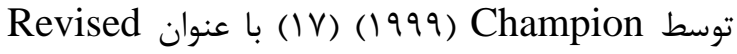
susceptibility, benefits and barriers scale for mammography screening

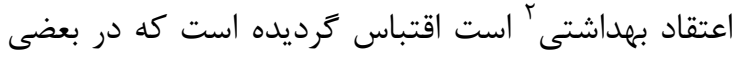
از موارد نياز به بومىسازى آن وجود داشته است. بنابراين

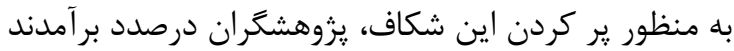

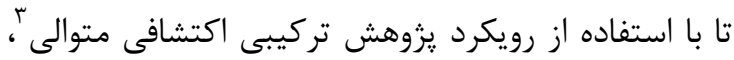

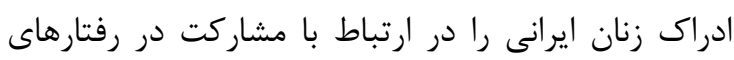

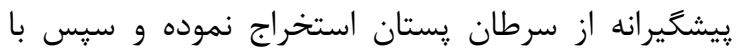

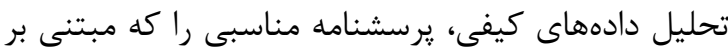

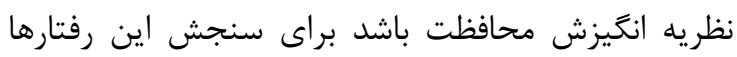

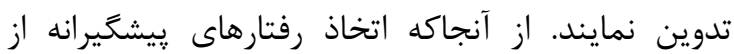

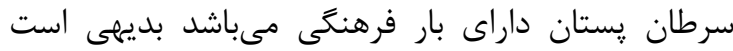

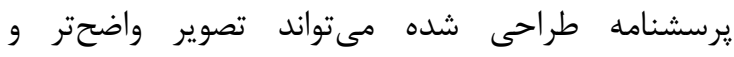

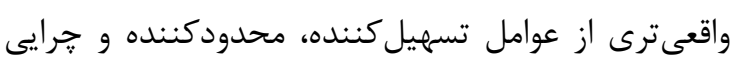
مشاركت يا عدم مشاركت در رفتارهاى جستجوى سلامت ترت يستان در زنان ايرانى ارايه نمايد.

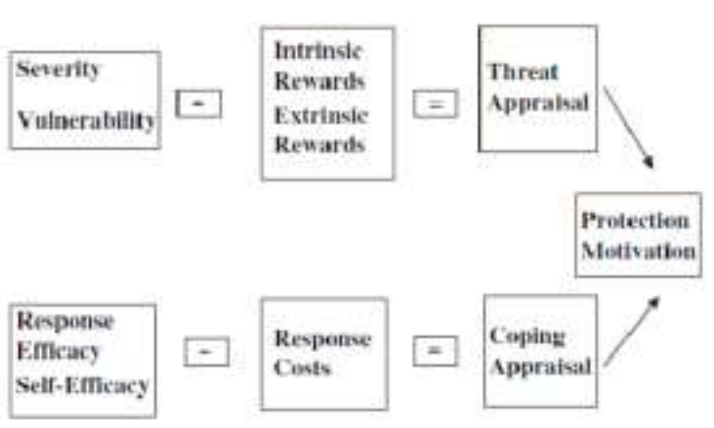

شكل ا: نماى شماتيك نظرى انگَيزش محافظت

\section{مواد و روشها}

در يزوهش حاضر از طرح تركيبى اكتشافى متوالى استفاده

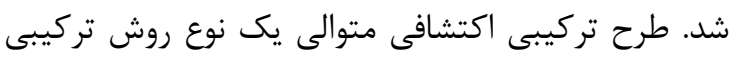

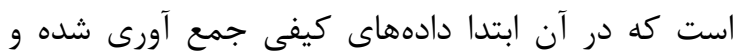

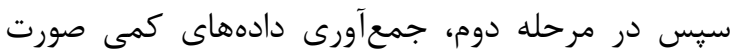

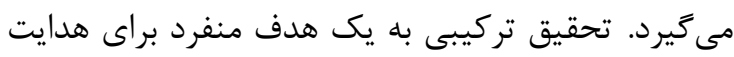

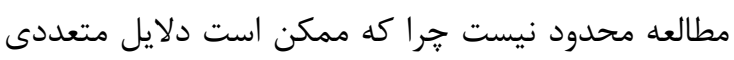
براى استفاده از اين متدولوزى وجود داشته باشد (1)).

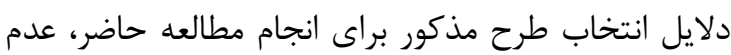

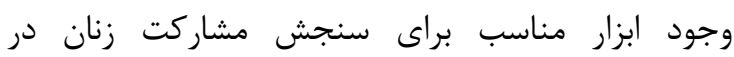

\footnotetext{
${ }^{2}$ Health belief model

${ }^{3}$ Sequential exploratory mixed method design
} 
اطمينان از صحت و يافتن هركّونه تويههاى هميوشان و تكرارى مورد بررسى قرار كرفت. برخى از گويهها كه به آنه نوعى تكرار شده بودند حذف شده و گَويههايى كه قابل

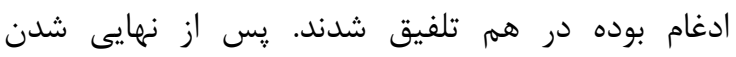
ييشنويس اوليه يرسشنامه، روايى صورى، محتوا و سازه آن بررسى شد. براى ارزيابى روايى محتوا، : برسشنامه

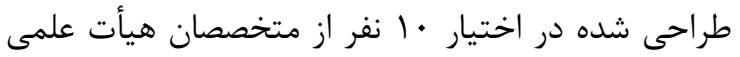

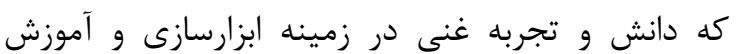

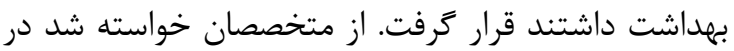

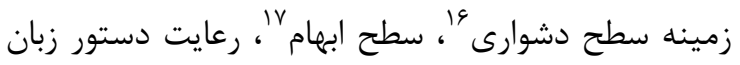

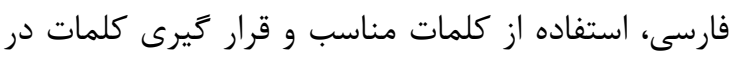

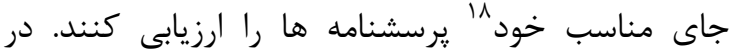

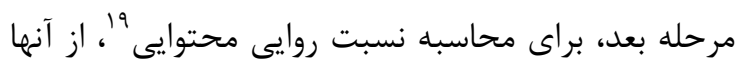

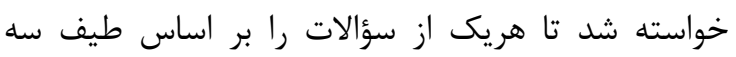

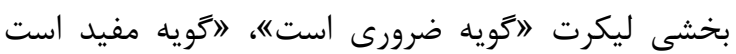

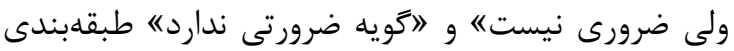

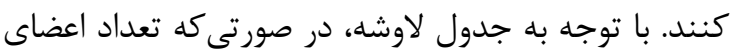

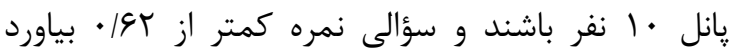
بايستى از يرسشنامه كنار كذاشته شود (آT). همجنين

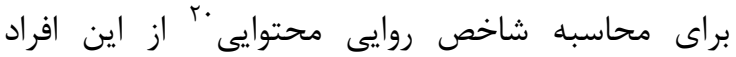

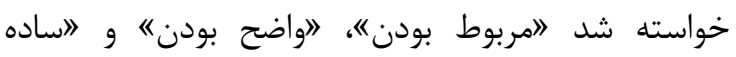

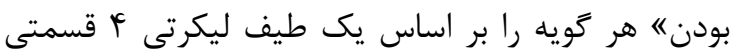
مشخص كنند. با محاسبه اين شاخص، گويههايى در

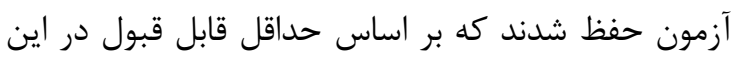

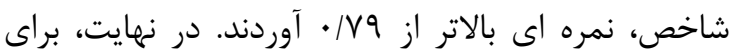

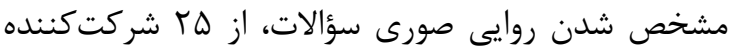

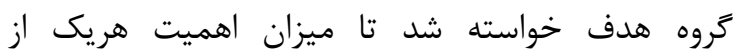

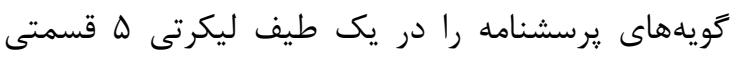

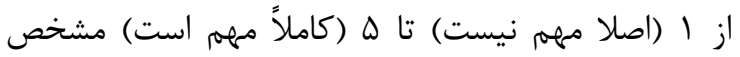
نمايند. ״ايايى يرسشنامه با روش همسانى درونى و ضريب آلفاى

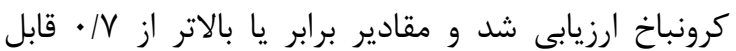
قبول در نظر گرفته شد. يرسشنامهها طى انجام مطالعه

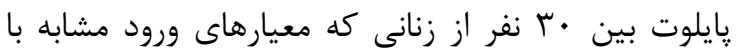

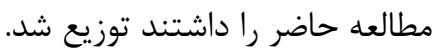

\footnotetext{
${ }^{16}$ Difficulty

${ }^{17}$ Ambiguous

${ }^{18}$ Item allocation

${ }^{19} \mathrm{CVR}$

${ }^{20} \mathrm{CVI}$
}

كدكذارى و تحليل دادهها مورد استفاده قرار كرفت. در

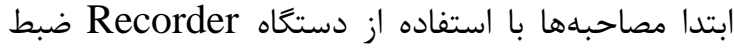

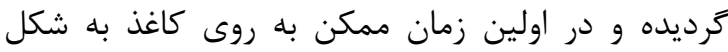

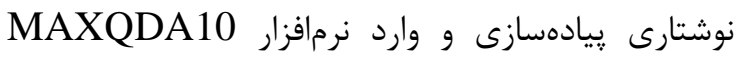

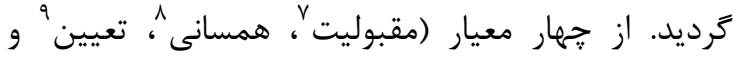

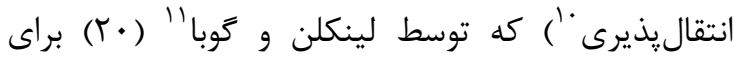

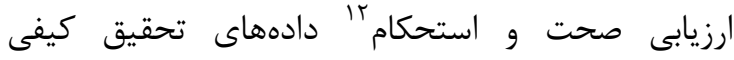
ييشنهاد گرديده استفاده شده است. از روشهاى دركيرى طولانى مدت با موضوع، مشاهده مداوم دادهها، مقايسه

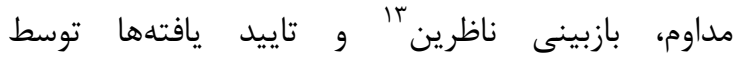

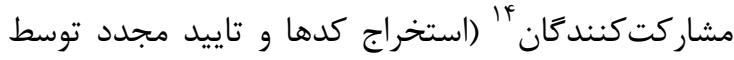

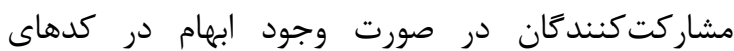
استخر اجى) استفاده شد.

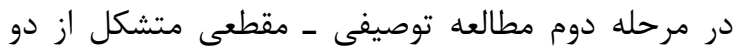

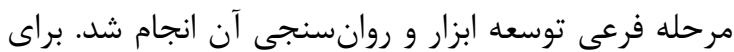
هر كدام از طبقات اصلى كه در مرحله كيفى شكل يافته

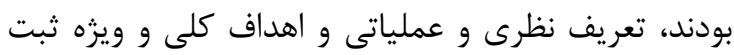
كرديد. هدف كلى ساخت آزمون در يزوهش حاضر،

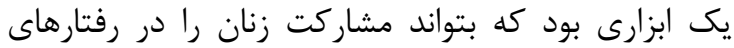

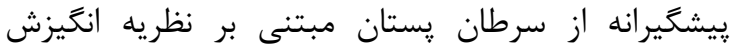

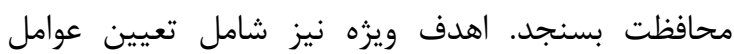
تسهيل كننده و محدودكننده مشاركت زنان شهر يزد در

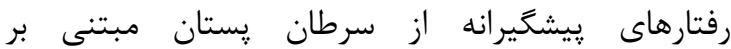

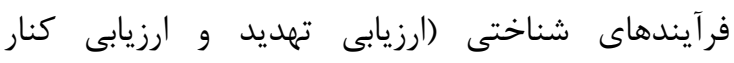

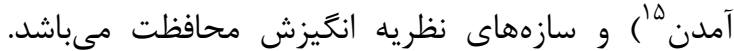
كويههاى اوليه به طور پيشنههادى منطبق بر كدهاى

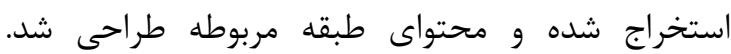

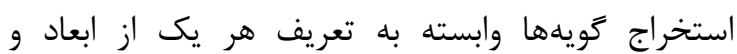
سازههاى مفهوم مورد مطالعه است. سوالات يرسشنامه به كونهاى طراحى شد كه ابعاد مشاركت زنان در رفتارهاى

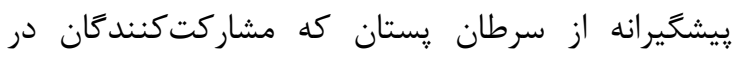
مصاحبههاى خود به آنها اشاره كرده بودند را دربربئيرد. كويههاى تدوين شده توسط اعضاى تيم يزوهش جهت

\footnotetext{
${ }^{7}$ Credibility

${ }^{8}$ Dependability or Consistency

${ }^{9}$ Conformability or Neutrality

${ }^{10}$ Transferability or Fittingness

${ }^{11}$ Lincoln \& Guba

${ }^{12}$ Trustworthiness \& Rigority

${ }^{13}$ Peer debriefing

${ }^{14}$ Member check

${ }^{15}$ Threat appraisal \& coping appraisal
} 
از مشاركت كنندكان در مراحل مطالعه، آزادى نمونهها در

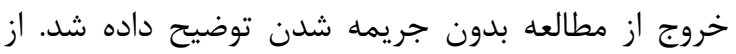

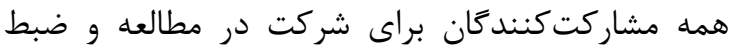
صدايشان اجازه كتبى كرفته شد.

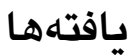

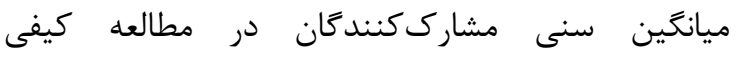

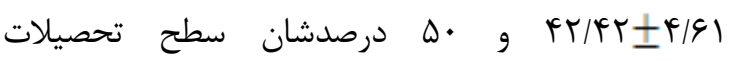

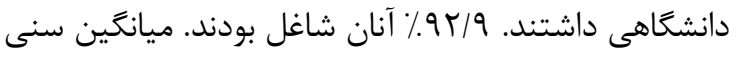
زنان در مرحله روانسنجى، 9/9V

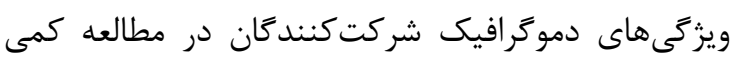
در جدول ال ارايه شده است. در بررسى روايى صورى كيفى بر اساس بازتابهايى كه از زنان دريافت شد تغييرات جزئى و ضرورى جهت برى وضوح

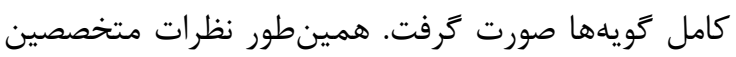

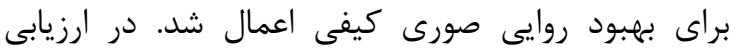
روايى صورى كمى، همه سازههاى نظريه انكَيزش محافظت

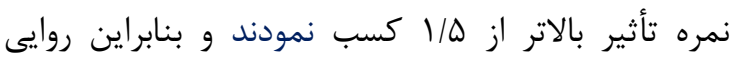
صورى يرسشنامه در اين مرحله تاييد شد. در بُعد روايى آنيى

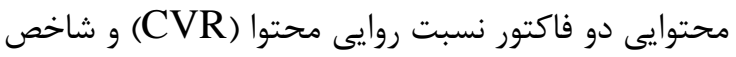

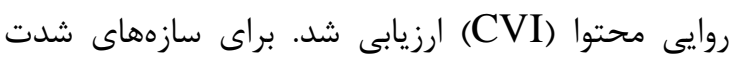

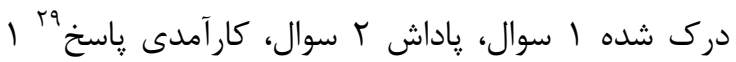

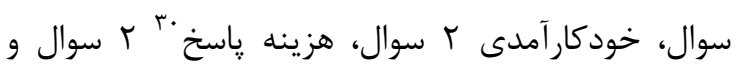

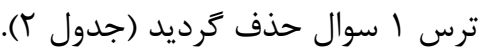

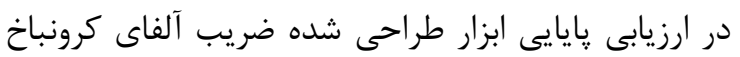

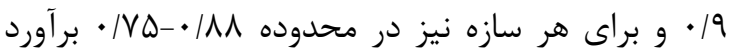

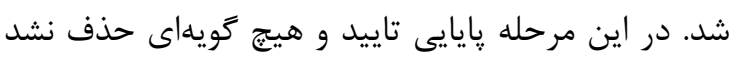

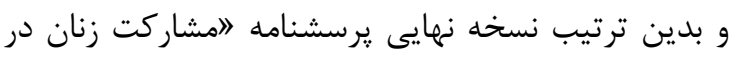

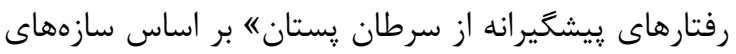
نظريه انكيزش محافظت داراى

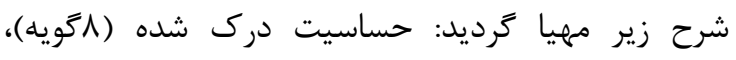

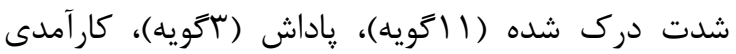

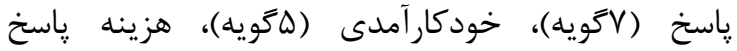

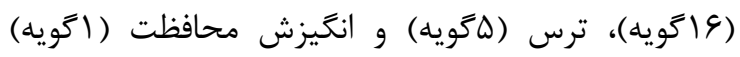

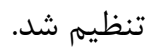

\footnotetext{
${ }^{29}$ Response efficacy

${ }^{30}$ Response cost
}

براى ارزيابى ساختار عاملى يرسشنامه از آنجاكه اطلاعات

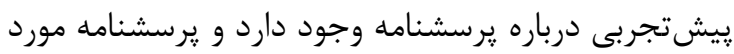
نظر بر مبناى يك نظريه (نظريه انخيزش محافظت)

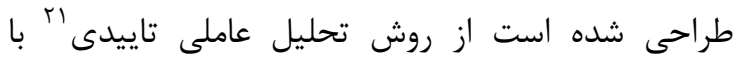
كمك نرمافزار آمارى Amos16 استفاده شد. تحليل راسيل عاملى تاييدى به يزوهشكر كمك مى كند تا دريابد مدل

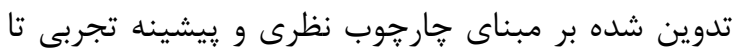

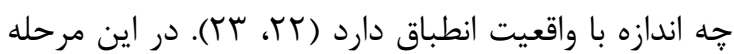

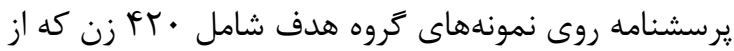
طريق نمونهَيرى خوشهاى انتخاب شده بودند اجرا شد.

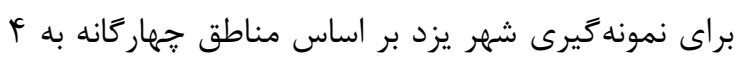

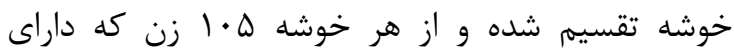

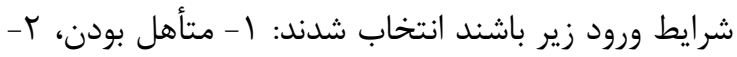

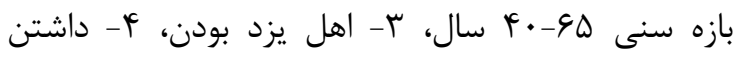
يرونده بهداشتى در همان منطقه، له- نداشتن سابقه ابتلا

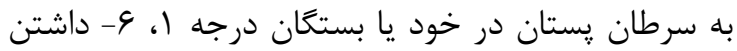

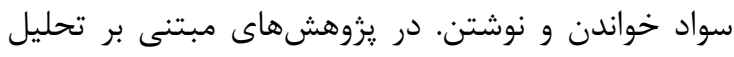

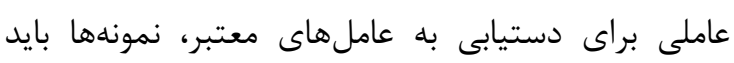

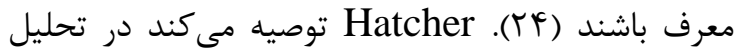

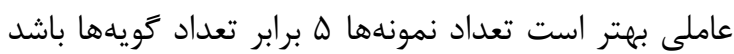

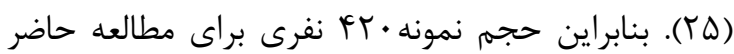

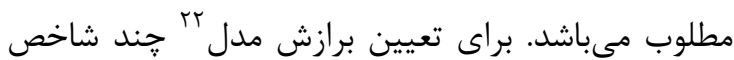

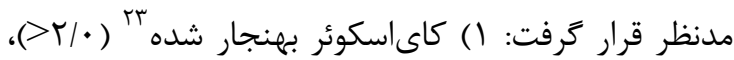

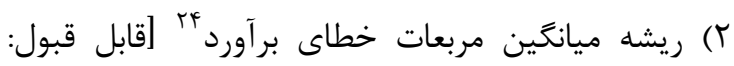

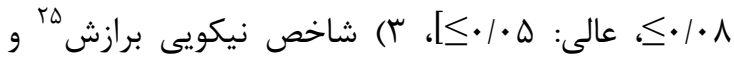

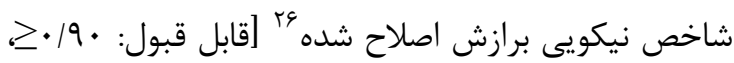

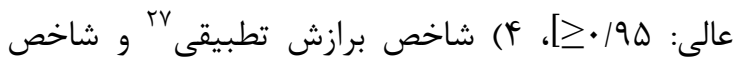

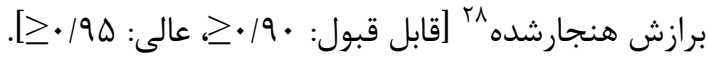
مطالعه حاضر مصوب كميته اخلاق معاونت تحقيقات و

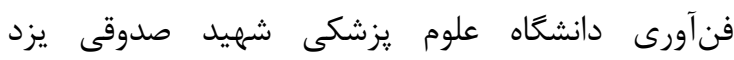

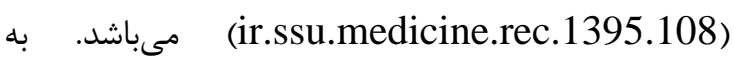
منظور رعايت موازين اخلاقى قبل از شروع مطالعه اهداف

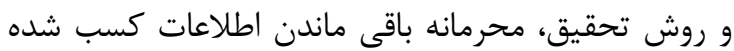

\footnotetext{
${ }^{21}$ Confirmatory factor analysis

${ }^{22}$ Model fit

${ }^{23}$ Normed Chi-Square (CMIN/df)

${ }^{24}$ Root Mean Squared Error of Approximation (RMSEA)

${ }^{25}$ Goodness-of-Fit Index

${ }^{26}$ Adjusted Goodness-of-Fit Index

${ }^{27}$ Comparative Fit Index

${ }^{28}$ Normed Fit Index
} 
جدول ا: مشخصات جمعيت شناختى زنان مطالعه در مرحله روانسنجى

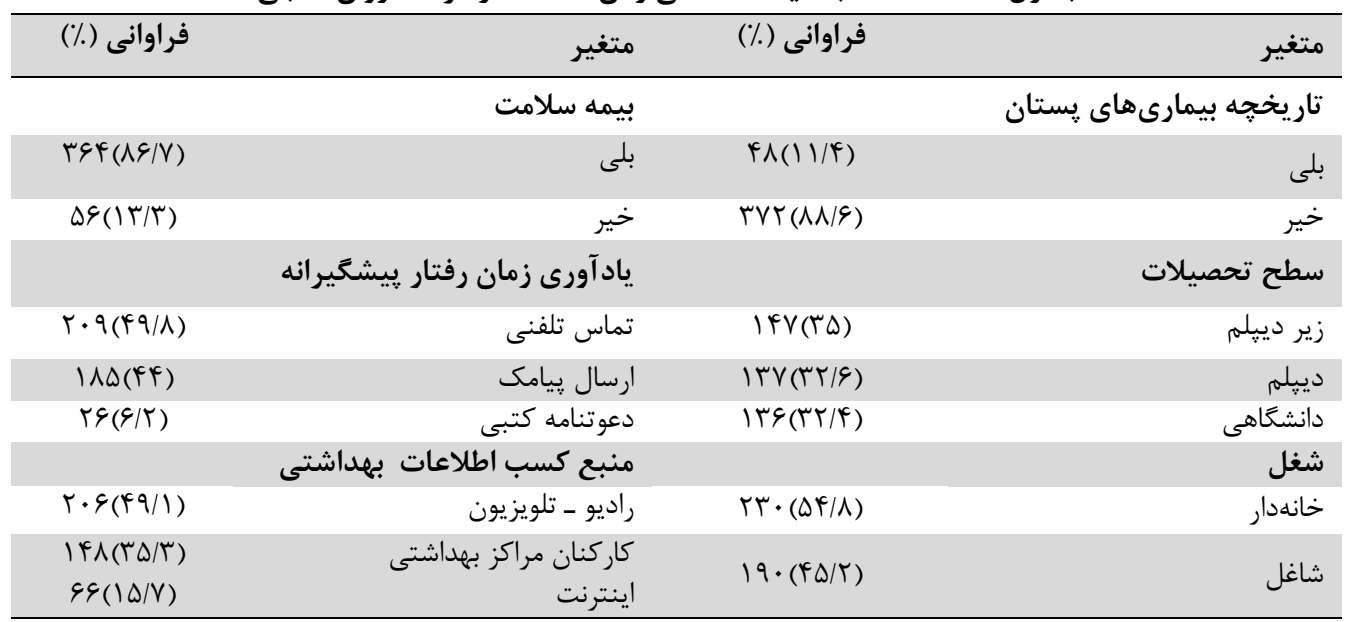

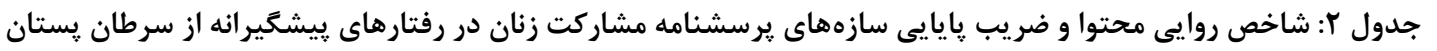

\begin{tabular}{|c|c|c|c|c|}
\hline آلفاى كرونباخ & CVI & CVR & نمونههايى از هر سازه & سازمها \\
\hline - & 1 & 1 & 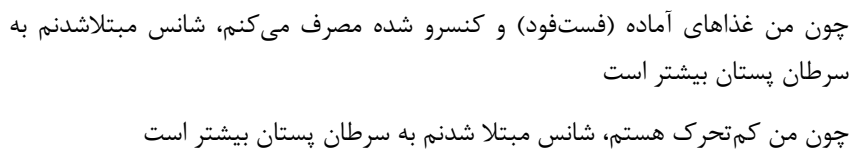 & درك شداسيت \\
\hline$\cdot / \wedge \Delta$ & 1 & 1 & 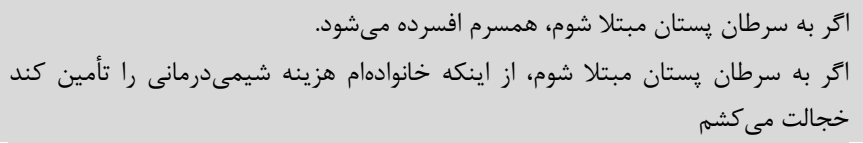 & شدت درى \\
\hline$\cdot / \mathrm{VA}$ & 1 & 1 & 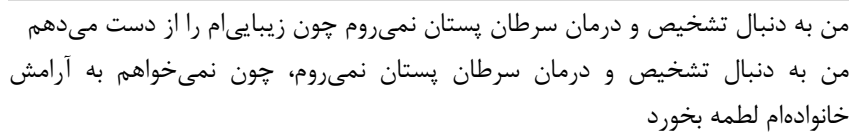 & ياداش \\
\hline$\cdot / V \Delta$ & $\cdot 19$ & $\cdot 11$ & 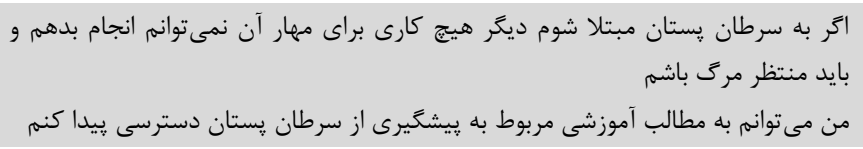 & خود كار آمدى \\
\hline - /AF & 1 & 1 & 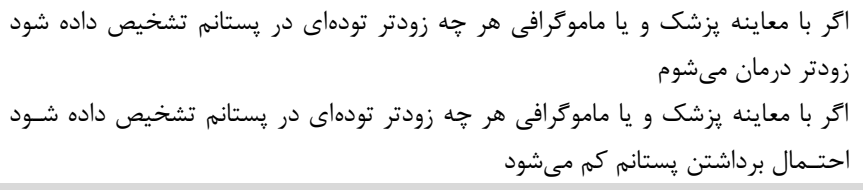 & كار آمدى ياسخ \\
\hline$\cdot / 1 \Lambda$ & 1 & $\begin{array}{c}1 \\
.19\end{array}$ & 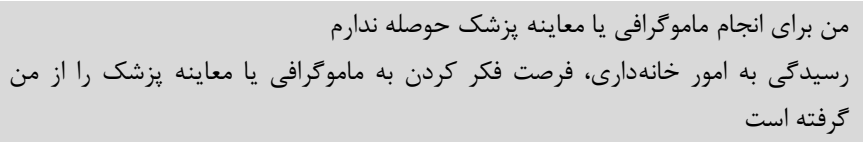 & هزينه هاسخ \\
\hline$\cdot / V \Lambda$ & 1 & 1 & اخر به سرطان پستان وحشتناكترين وازٔهاى است كه در طول عمرم شنيدهام & ترس \\
\hline$\cdot / V F$ & 1 & 1 & 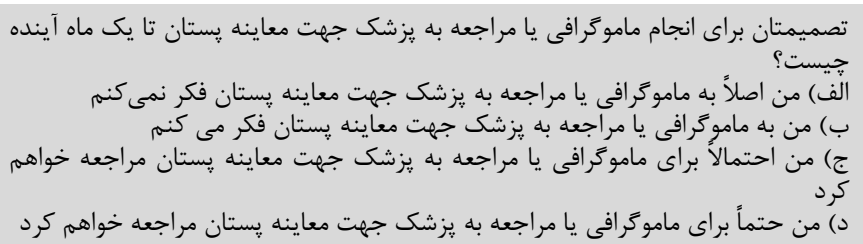 & محافظت \\
\hline
\end{tabular}


طراحى كرديده است تاييد شد؛ جراكه مقدار RMSEA

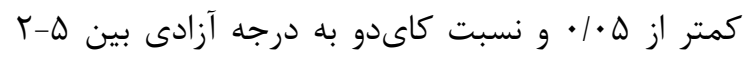

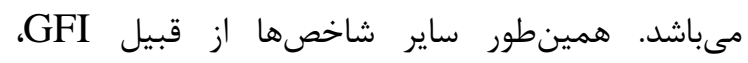

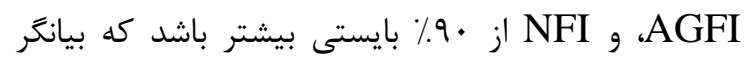
برازش مطلوب مدل حاضر مى باشد (جدول باوزأ).
هر كويه به صورت طيف ليكرت ه امتيازى از كاملا موافقم

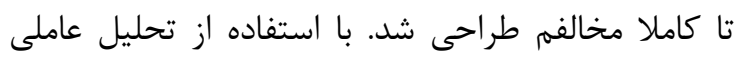

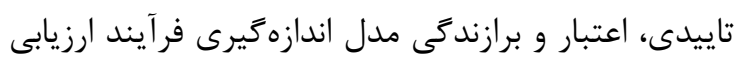

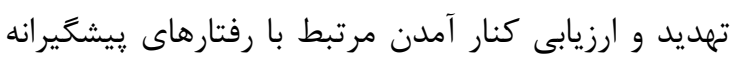

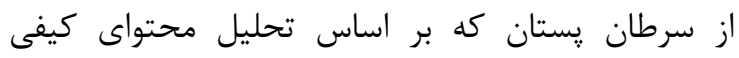
(qualitative content analysis)

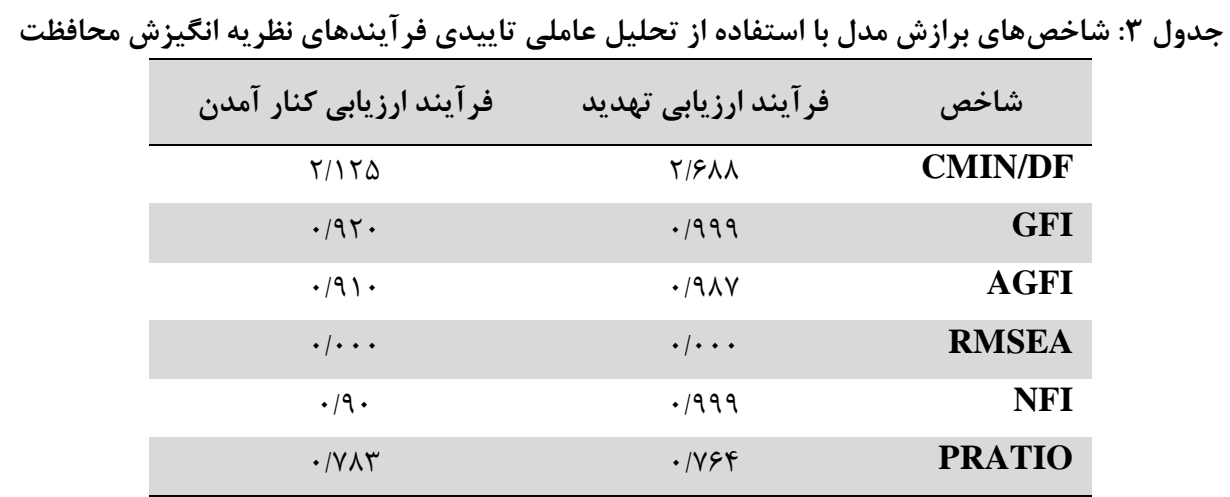

جدول F. نتايج تحليل عاملى سازههاى برسشنامه مشاركت زنان در رفتارهاى بيشگيرانه از سرطان بستان

\begin{tabular}{|c|c|c|c|c|c|c|c|c|c|c|c|c|c|c|c|}
\hline \multicolumn{2}{|c|}{ محافظت انعيزش } & \multicolumn{2}{|c|}{ ترس } & \multicolumn{2}{|c|}{ هزينه ياسخ } & \multicolumn{2}{|c|}{ كار آمدى } & \multicolumn{2}{|c|}{ خود كار آمدى } & \multicolumn{2}{|c|}{ 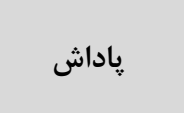 } & \multicolumn{2}{|c|}{ شدت درى } & \multicolumn{2}{|c|}{ حساسيت درى } \\
\hline بار & كويه & بار & كويه & بار & كويه & بار & كويه & بار & كويه & بار & كويه & بار إ & تويه & بار & تويه \\
\hline عاملى & & عاملى & & عاملى & & عاملى & & عاملى & & عاملى & & عاملى & & عاملى & \\
\hline \multirow[t]{16}{*}{$\cdot / \mathrm{VV}$} & 1 & $\cdot / D T$ & 1 & $\cdot / \mathrm{Vr}$ & 1 & $\cdot 199$ & 1 & $\cdot / \mathrm{V}$ & 1 & $\cdot \mid \Delta F$ & 1 & $\cdot|\Lambda|$ & 1 & .190 & 1 \\
\hline & & $\cdot / 4$ & r & $\cdot 19 \mathrm{~V}$ & r & $\cdot / 4$ & r & $\cdot 109$ & r & $\cdot \mid \Delta \Phi$ & r & $\cdot \mid \Delta S$ & r & - /VG & r \\
\hline & & $\cdot / V T$ & r & $\cdot 1 \Delta 9$ & r & $\cdot / \Delta T$ & r & $\cdot / 49$ & r & $\cdot / V 1$ & r & $\cdot 199$ & r & $\cdot / \mathrm{VV}$ & r \\
\hline & & $\cdot 109$ & f & $\cdot 10$ & f & $\cdot 19$ & r & $\cdot|\Delta|$ & r & & & $\cdot \mid \Delta \Lambda$ & r & . IAT & f \\
\hline & & $\cdot / V \&$ & $\Delta$ & . & $\Delta$ & $\cdot / V r$ & $\Delta$ & $\cdot / D T$ & $\Delta$ & & & $\cdot / V \Delta$ & $\Delta$ & $\cdot \mid \mathrm{VI}$ & $\Delta$ \\
\hline & & & & $\cdot / \Delta T$ & 9 & $\cdot \mid \Delta 9$ & 9 & & & & & $\cdot / V 1$ & 4 & $\cdot \mid \Delta V$ & 9 \\
\hline & & & & $\cdot / \mathrm{q}$ & v & $\cdot \mid 9 F$ & v & & & & & . IOT & v & $\cdot|9|$ & v \\
\hline & & & & $\cdot / V$ & $\wedge$ & & & & & & & - /AT & $\wedge$ & $\cdot / V V$ & $\wedge$ \\
\hline & & & & $\cdot / 4 q$ & 9 & & & & & & & $\cdot|9|$ & 9 & & \\
\hline & & & & $\cdot|\Delta|$ & 1. & & & & & & & $\cdot \mid \Delta S$ & 1. & & \\
\hline & & & & $\cdot|V|$ & 11 & & & & & & & $\cdot / V r$ & 11 & & \\
\hline & & & & $\cdot / \Delta T$ & IT & & & & & & & & & & \\
\hline & & & & $\cdot / \Lambda$ & Ir & & & & & & & & & & \\
\hline & & & & $\cdot / \Delta T$ & If & & & & & & & & & & \\
\hline & & & & $\cdot \mid \& V$ & 10 & & & & & & & & & & \\
\hline & & & & $\cdot 10$ & 19 & & & & & & & & & & \\
\hline
\end{tabular}


انخيزش را تبيين نمايد (YV). به نظر مىرسد متفاوت بودن مشخصات افراد گروه هدف دليل احتمالى جنين نمايد تفاوتهايى با نتايج مطالعه حاضر باشد.

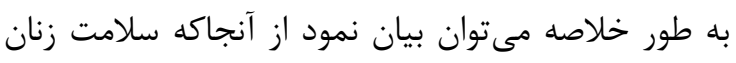
تضمين كننده سلامت خانواده و جامعه است لذا دمان دستيابى إنى به توسعه بهداشت در جهان بدون توجه به اهميت سلامت

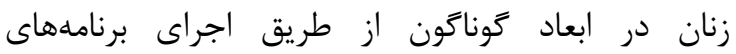
توانمندسازى آنان ممكن نيست (YN) مديران و برنامهريزان دولتى و غيردولتى تأمين تسهيلات

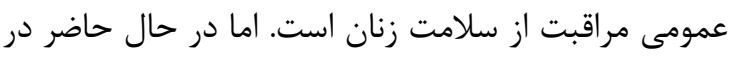

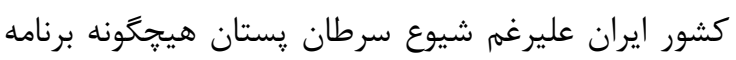

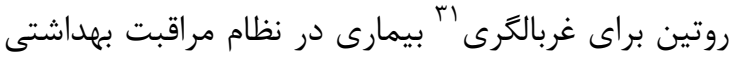

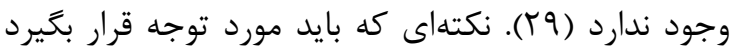

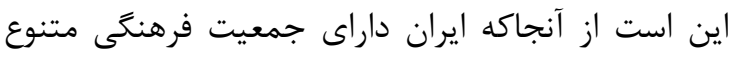

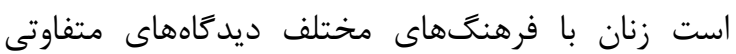
درباره سرطان يستان و راهبردهاى پِيشگيرى از آن دارند

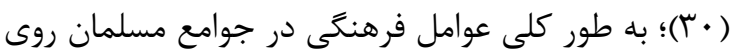

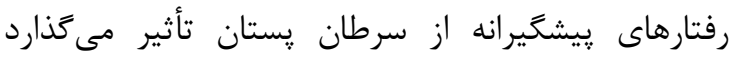

محدوديتهاى مطالعه حاضر را مىتوان بدين صورت

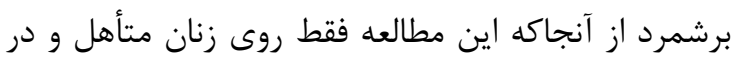

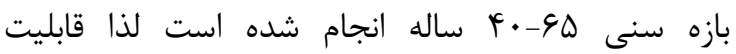

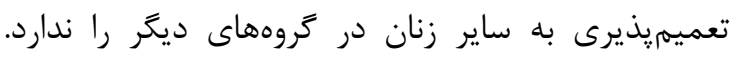

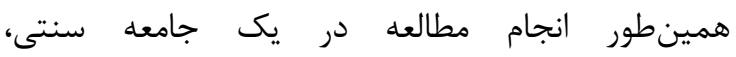

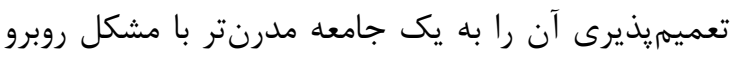

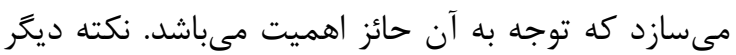
اينكه همواره ابزارهاى ساخته شده با ابزارهاى مشابـ إنهائ

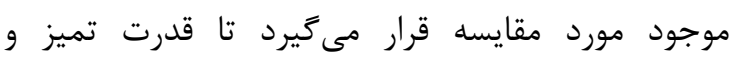

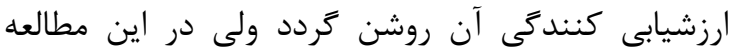

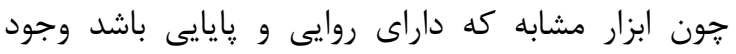

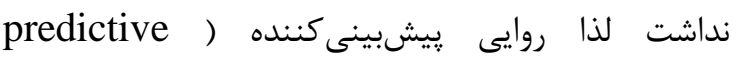
(validity نشد؛ در اين طالعه همانطور كه نتايج جدول أ نشان داد

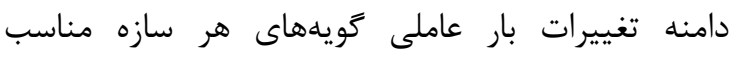

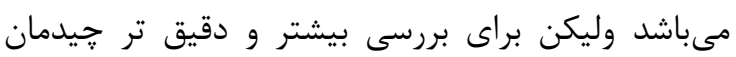

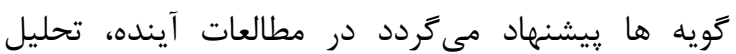
عاملى اكتشافى مدنظر واقع شود.

\footnotetext{
${ }^{31}$ screening
} 


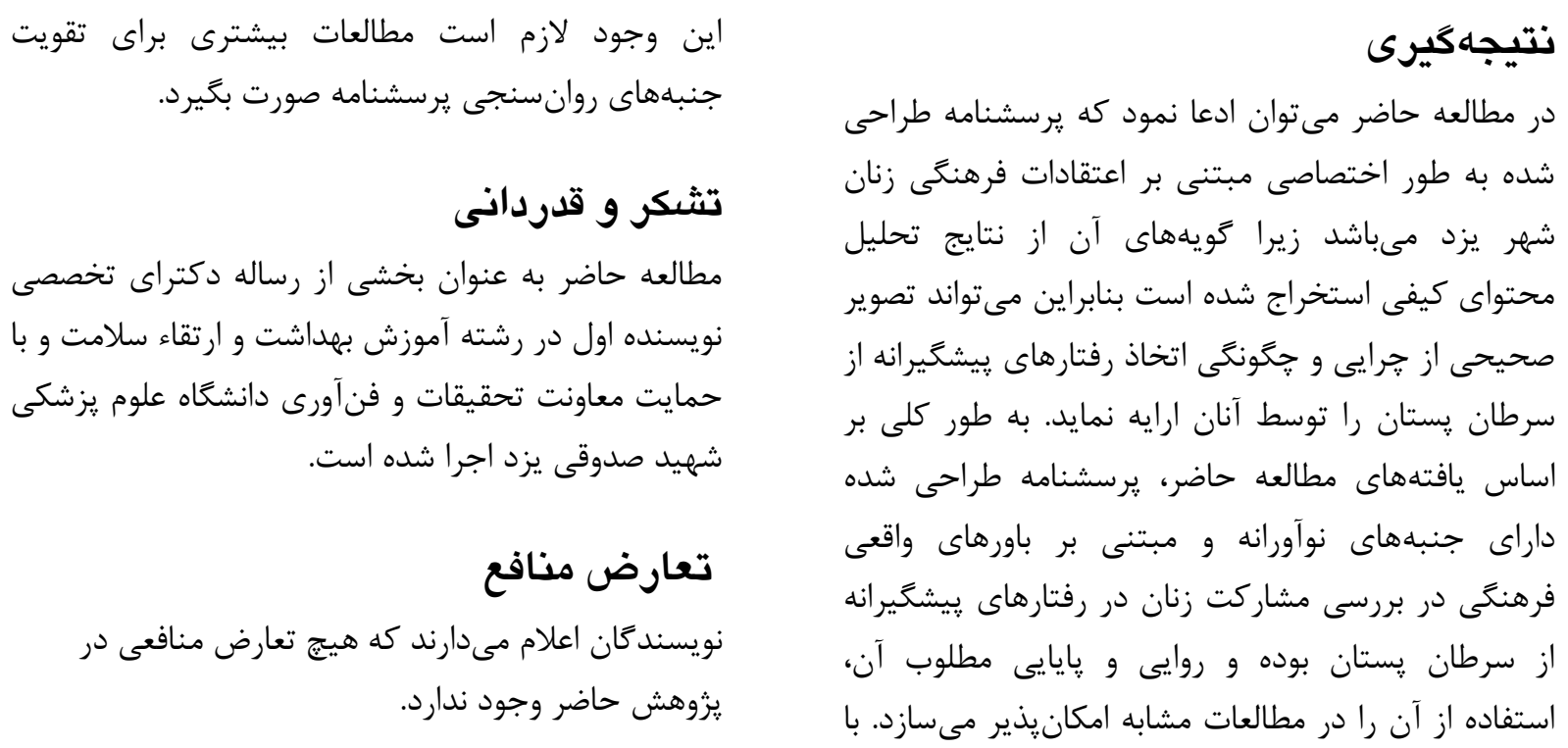

\section{نتيجه "نيرى}

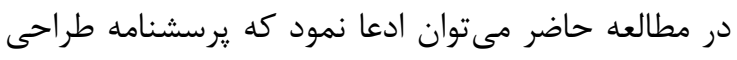

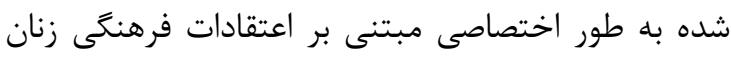

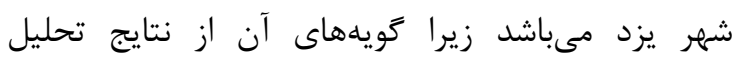

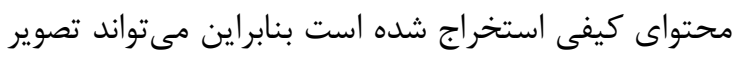

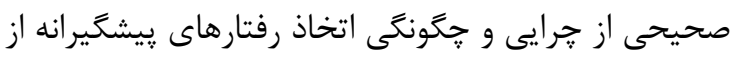

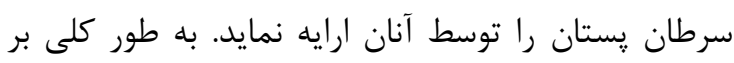

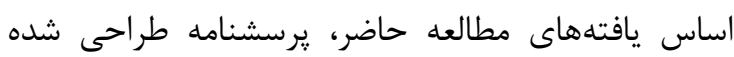

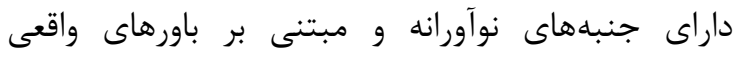

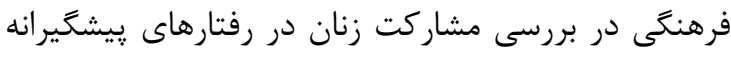

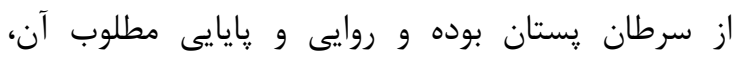

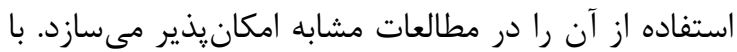

\section{References}

1. Shadi Kolahdoozan MD M, Alireza Sadjadi MD M, Radmard AR, Hooman Khademi MD M. Five common cancers in Iran. Archives of Iranian Medicine. 2010;13(2):143.

2. Jazayeri SB, Saadat S, Ramezani R, Kaviani A. Incidence of primary breast cancer in Iran: Ten-year national cancer registry data report. Cancer Epidemiology. 2015;39(4):519-27.

3. Jarvandi S, Montazeri A, Harirchi I, Kazemnejad A. Beliefs and behaviours of Iranian teachers toward early detection of breast cancer and breast self-examination. Public Health. 2002;116(4):245-9.

4. National Cancer Registry Report, 2008. Tehran, cancer administration. Noncommunicable diseases sector, Iranian center for diseases control and prevention. 2012. [In Persian]

5. Harirchi I, Kolahdoozan S, Karbakhsh M, Chegini N, Mohseni SM, Montazeri A, et al. Twenty years of breast cancer in Iran: downstaging without a formal screening program. Annals of Oncology. 2011;22(1):937.

6. Harirchi I, Karbakhsh M, Kashefi A, Momtahen AJ. Breast cancer in Iran: results of a multi-center study. Asian Pac J Cancer Prev. 2004;5(1):24-7.

7. Lamyian M, Heidarnia A, Ahmadi F, Faghihzadeh S, AguilarVafaie M. Women's prospect of breast cancer early detection behavior: a qualitative research. Journal of Birjand University of Medical Sciences. 2008;15(3):88-102. [In Persian]

8. Grunfeld EA, Hunter MS, Ramirez AJ, Richards MA. Perceptions of breast cancer across the lifespan. Journal of psychosomatic research. 2003;54(2):141-6.

9. Mousavi SM, Montazeri A, Mohagheghi MA, Jarrahi AM, Harirchi I, Najafi M, et al. Breast cancer in Iran: an epidemiological review. The breast Journal. 2007;13(4):383-91.

10. Montazeri A, Ebrahimi M, Mehrdad N, Ansari M, Sajadian A. Delayed presentation in breast cancer: a study in Iranian women. BMC women's health. 2003;3(1):1.

11. Thomas E, Escandón S, Lamyian M, Ahmadi F, Setoode SM, Golkho S. Exploring Iranian Women's Perceptions Regarding Control and Prevention of Breast Cancer. The Qualitative Report. 2011;16(5):1214-29.

12. Hajian $\mathrm{S}$, Vakilian $\mathrm{K}$, Najabadi KM, Hosseini J, Mirzaei HR. Effects of education based on the health belief model on screening behavior in high risk women for breast cancer, Tehran, Iran. Asian Pac J Cancer Prev. 2011;12(1):49-54.

13. Glanz K, Rimer BK, Viswanath K .Health behavior and health education: theory, research, and practice: John Wiley \& Sons; 2008: 130 . 
14. MacDonell K, Chen X, Yan Y, Li F, Gong J, Sun $\mathrm{H}$, et al. A protection motivation theorybased scale for tobacco research among Chinese youth. Journal of Addiction Research \& Therapy. 2013 July 8;4:154.

15. Yan Y, Jacques-Tiura AJ, Chen X, Xie N, Chen J, Yang N, et al. Application of the protection motivation theory in predicting cigarette smoking among adolescents in China. Addictive Behaviors. 2014;39(1):181-8.

16. Lwin M. Examining Asian Women's Motivations to Undergo Breast Cancer Screening. J Women's Health Care. 2014;3(158):2167-0420.

17. Champion VL. Revised susceptibility, benefits, and barriers scale for mammography screening. Research in nursing \& health. 1999;22(4):341-8.

18. Andrew S, Halcomb E. Mixed methods research for nursing and the health sciences: Wiley Online Library; 2009.

19. Burnard P. A method of analysing interview transcripts in qualitative research. Nurse Education Today. 1991;11(6):46-61.

20. Shenton AK. Strategies for ensuring trustworthiness in qualitative research projects. Education for Information. 2004;22(2):63-75.

21. Lawshe $\mathrm{CH}$. A quantitative approach to content validity1. Personnel Psychology. 1975;28(4):563-75.

22. Brown TA . Confirmatory factor analysis for applied research: Guilford Publications; 2014:128.

23. Harrington D. Confirmatory factor analysis: Oxford University Press; 2009: 163.
24. Kline P. An easy guide to factor analysis: Routledge; 2014: 120.

25. Hatcher L. Developing measurement models with confirmatory factor analysis. A step-bystep approach to using the SAS® System for factor Analysis and Structural Equation Modeling (ed). 1994:249-342.

26. Grove SK, Burns N, Gray JR. Understanding nursing research: Building an evidence-based practice: Elsevier Health Sciences; 2014: 245.

27. Helmes AW. Application of the protection motivation theory to genetic testing for breast cancer risk. Preventive Medicine. 2002;35(5):453-62

28. .World Health Organization. The world health report 2000: health systems: improving performance. World Health Organization; 2000 .

29. Lamyian M, Hydarnia A, Ahmadi F, Faghihzadeh S, Aguilar-Vafaie ME. Barriers to and factors facilitating breast cancer screening among Iranian women: a qualitative study. Eastern Mediterranean Health Journal. 2007;13(5): 1160-9.

30. Smigal C, Jemal A, Ward E, Cokkinides V, Smith R, Howe HL, et al. Trends in breast cancer by race and ethnicity: update 2006. CA: a cancer journal for clinicians. 2006;56(3):16883.

31. Avci IA. Factors associated with breast selfexamination practices and beliefs in female workers at a Muslim community. EuropeanJournal of Oncology Nursing. 2008;12(2):127-33. 